\title{
An exploratory descriptive study of accent shift in Northern East Cree
}

\author{
Katharine Davies \\ University of British Columbia
}

Northern East Cree has several / $+\mathrm{h} /$ morphemes, which, when suffixed onto a word, add meanings such as inanimate plurality or animate obviation. Literature on these morphemes has yet to describe the impressionistic accent shift that accompanies $/+\mathrm{h} /$ suffixation onto a word. In this article findings are presented from an exploratory descriptive study in which citation forms with and without the $/+\mathrm{h} /$ morphemes are compared, examining how accent shift is acoustically realized, as well as the relevance of pitch slope and modal voicing. The results do not align with previous analyses of the $/+\mathrm{h} /$ morphemes' properties. Rather, it is possible that words without $/+\mathrm{h} /$ have a falling tone pattern, whereas words with $/+\mathrm{h} /$ have a level tone pattern, suggesting that pitch slope, in combination with modal voice, may be the best diagnostic of the presence of $/+\mathrm{h} /$ morphemes.

\section{Introduction}

Northern East Cree (NE Cree) has several / $+\mathrm{h} /$ morphemes, which, when suffixed onto a word add meanings such as inanimate plurality or animate obviation. Literature on these $/+\mathrm{h} /$ morphemes captures their historical origins and the grammatical contexts in which they appear. What current literature has yet to describe, however, is the impressionistic accent shift that accompanies $/+\mathrm{h} /$ suffixation onto a word (Dyck et al. 2006), as well as anecdotal changes in voicing. In this article, findings are presented from an exploratory descriptive study in which citation forms with and without the $/+\mathrm{h} /$ morphemes are compared, describing how the impressionistic accent shift from a non-final syllable to the final syllable may be acoustically realized on measures of pitch on the ultimate, penultimate, and antepenultimate syllables. Descriptive observations on how voicing and pitch slope may be used by NE Cree speakers in relation to the $/+\mathrm{h} /$ morpheme are also provided.

The results of this study do not align with previous analyses of the $/+\mathrm{h} /$ morphemes' properties. The three speakers were not found to consistently shift accent with the addition of the $/+\mathrm{h} /$ morpheme. Rather, the findings show that it is possible the $/ \mathrm{h} /$ morphemes may have both segmental and prosodic effects on the production of the words that carry these suffixes; that words without $/ \mathrm{h} /$ may have a falling tone pattern, whereas words with $/+h /$ may have a level tone pattern. It is suggested that pitch slope, in combination with modal voice, may the best diagnostic of the presence of $/+\mathrm{h} /$ in NE Cree. However, future research comprising a stronger research methodology is required to refute or support these findings.

\subsection{NE Cree background}

NE Cree is part of the Cree-Montagnais (Innu)-Naskapi (CMN) dialect complex, of the Algonquian language family (MacKenzie 1980). The CMN complex divides into Western and Eastern languages (MacKenzie 1980). There is also some dialectal variation in NE Cree, notably between the Coastal and Inland sub-dialects (MacKenzie 1980). The differentiation between Coastal and Inland sub-dialects of NE Cree is, however, not well-documented (see Dyck et al. 2010 for more information on the Coastal and Inland sub dialectal variation). This study uses recordings of speakers from Chisasibi, Quebec, one of nine Northern East Cree communities in the James Bay area (http://www.chisasibi.org). Two speakers speak an 
Inland sub-dialect, while the third speaks a Coastal dialect. The consonant inventory of NE Cree is listed below in Table 1 (Dyck et al. 2006).

Table 1. Consonants

\begin{tabular}{cccccc}
\hline & Labial & Alveolar & Palatal & Velar & Glottal \\
\hline Stops & $\mathrm{p}$ & $\mathrm{t}$ & $\mathrm{ch}[\mathrm{t}]$ & $\mathrm{k}, \mathrm{kw}$ & \\
Fricatives & & $\mathrm{s}$ & $\mathrm{sh}[\mathrm{k}]$ & & \\
Nasals & $\mathrm{m}$ & $\mathrm{n}$ & & & $\mathrm{h}$ \\
Glides & $\mathrm{w}$ & & $\mathrm{y}[\mathrm{j}]$ & & \\
\hline
\end{tabular}

Vowels in NE Cree are historically categorized as either "long" or "short". At present, while phonologically relevant, vowel length is phonetically realized as a distinction between tense (formerly long) and lax (formerly short) (MacKenzie 1980). This distinction is relevant for accent placement, as discussed in section 1.2. An orthographic representation of the vowel inventory is provided below in Table 2 (Dyck et al. 2006). Diphthongs in NE Cree pattern with heavy vowels. The diphthongs are listed in Table $3 .{ }^{1}$

Table 2. Vowels

\begin{tabular}{cccc}
\hline & \multicolumn{2}{c}{ Long Vowels } & \multicolumn{2}{c}{$\begin{array}{c}\text { Short Vowels } \\
\text { (Historically long and tense) }\end{array}$} & \multicolumn{2}{c}{ (Historically short and lax) } \\
\hline \multirow{2}{*}{$\hat{\mathrm{i}}$} & $\hat{\mathrm{u}}$ & $\mathrm{i}$ & $\mathrm{u}$ \\
& $\hat{\mathrm{a}}$ & & \multicolumn{2}{c}{$\mathrm{a}$} \\
\hline
\end{tabular}

Table 3. Diphthongs

\begin{tabular}{|c|c|c|}
\hline wî & wâ & uy [ซy] \\
\hline$\hat{1} \mathrm{~W}$ & âw [aw] & \\
\hline iw [iw, u:, o:] & aw [aw] & \\
\hline wîw [wiw] & wâw [w $\left.\mathfrak{p}^{\mathrm{w}}, \mathfrak{p}^{\mathrm{w}},{ }^{\mathrm{w}} \mathrm{\jmath}^{\mathrm{w}}, \mathrm{\jmath}^{\mathrm{w}}\right]$ & \\
\hline
\end{tabular}

Maximally, non-final syllables in NE Cree consist of an onset consonant (C), a nucleus (V), a coda (C), forming a (C)V(C) template (Dyck et al. 2006), as illustrated below in Table 4. Non-final coda consonants can only be fricative and are limited to the consonants $\left[\mathrm{h}, \mathrm{s}, \int\right]$, whereas $\left[\mathrm{h}, \mathrm{s}, \int, \mathrm{n}, \mathrm{m}\right]$ are permitted in wordfinal codas. (MacKenzie 1980; Dyck et al. 2006). However, consonants other than [h, s, $\left.\int, \mathrm{n}, \mathrm{m}\right] \mathrm{can}$ be found word-finally. For example, words such as miht 'firewood (sg.)', which end in an impermissible coda segment, are typical. To account for this possibility, the existence of an 'appendix' position for 'extra' wordfinal consonants is assumed, following Dyck et al. (2006).

\footnotetext{
${ }^{1}$ In this paper, I use the ' $\wedge$ ' diacritic to indicate a long vowel, following conventional NE Cree orthography.
} 
Table 4. Syllable template

\begin{tabular}{ccc}
\hline $\mathrm{C}_{\text {onset }}$ & $\mathrm{V}$ & $\mathrm{C}_{\text {coda }}$ \\
\hline $\begin{array}{c}\text { Any } \\
\text { consonant }\end{array}$ & Any vowel or diphthong & {$[\mathrm{h}, \mathrm{s}, \mathrm{S}, \mathrm{n}, \mathrm{m}]$} \\
\hline
\end{tabular}

The full NE Cree word syllable template is presented in Table 5 (Dyck et al. 2006).

Table 5. Word template with appendix

\begin{tabular}{|c|c|c|}
\hline \multirow[t]{2}{*}{ \# } & $\sigma^{\mathrm{n}}$ & 'Appendix' (C $\left.\mathrm{C}_{\text {onset }}\right)$ \\
\hline & Any number of syllables as in Table 4 & Any consonant Table 1 \\
\hline
\end{tabular}

\subsection{Pitch accent in NE Cree}

Each word in NE Cree contains one accented syllable, which correlates with a higher pitch, and to a lesser degree, intensity, in relation to the surrounding syllables in that word (Dyck et al. 2006). The placement of accent in NE Cree is traditionally described as following one of two patterns: (a) the non-final accent pattern and, (b) the final accent pattern (MacKenzie 1980; Dyck et al. 2006). MacKenzie (1980) observes that in the non-final accent pattern, words are accented on either the penultimate syllable or the antepenultimate syllable. When the penultimate syllable is long, accent falls on the penultimate syllable. When the antepenultimate vowel is long, and the penultimate vowel is short, accent falls on the long antepenultimate syllable. When both antepenultimate and penultimate vowels are short, the accent can fall on either syllable (MacKenzie 1980). This pattern can be explained by assuming NE Cree is quantity sensitive whereby historically long vowels are heavy. Refer to Table 6 for examples of the non-final accent pattern.

(1) Non-final accent pattern:
a. 'kâ.ni.chî 'sweater'
b. 'chî.mân 'boat'
c. ni. 'shi.kî 'my skin'
d. 'nu.kum 'my grandmother'
e. 'mis.chi.shin 'shoe'

Literature on NE Cree (MacKenzie 1980; Dyck et al. 2006) suggests that the final accent pattern occurs with the addition of one of two homophonous morphemes, both represented phonologically as $/+\mathrm{h} /$, which encode either inanimate plural or animate obviative. ${ }^{2}$ With the addition of $/+\mathrm{h} /$, stress-attracting morphemes, the accent shifts to the final syllable from any non-final syllable. Examples of the final accent pattern are provided in Table 7.

(2) Final accent pattern:

a. kâ.ni. 'chî. $(+h)$ 'sweaters'

b. wâ. 'ti.kw(+h) 'holes, dens'

c. wâ.pu.yâ.n( $(+\mathrm{h})$ 'blankets'

d. îh. 'ku.m $(+h)$ 'someone's grandmother'

e. mis.chi. 'shi.n $(+h)$ 'shoes'

\footnotetext{
${ }^{2}$ NE Cree orthography is developing and words with the word-final /+h/ are not consistently spelled with an "h" wordfinally (Dyck et al. 2006). For clarity and consistency, the $/+h /$ morpheme will be represented as $(+h)$.
} 


\subsection{Voicing}

Researchers studying NE Cree have anecdotally noted voice quality changes word-finally in the context of $\mathrm{a} /+\mathrm{h} /$ morpheme NE Cree in addition to pitch accent shift (Dyck p.c., September 2011). These observations have yet to be documented in the literature. An exploratory description of voice quality used by the three speakers in this study will be provided, as it relates to the presence or absence of the $/+h / m o r p h e m e$.

\section{The current study}

The aim of the current study is to provide an exploratory description of accent shift associated with the / $+\mathrm{h} /$ morpheme in NE Cree and associated word-final phenomena. To meet this aim, three research questions were created. First, does accent shift from the non-final to the final syllable in the tokens provided by three speakers of NE Cree? Second, what role, if any, does voice quality play in the addition of the $/+h /$ morpheme? Last, what other phonetic phenomena can be observed by comparing citations of words with and without this morpheme? It is predicted that accent will shift from the non-final to the final syllable in the tokens provided by all three speakers and that a shift in accent will be accompanied by a change in voice quality.

\subsection{Data collection}

Data for this study comes from the speech of three speakers from Chisasibi, Quebec. The three speakers, LBS, MN, and JN, are all native speakers of both NE Cree and English. LBS speaks the Coastal sub-dialect of NE Cree, while MN and JN speak the Inland sub-dialect. Differences between sub-dialectal Coastal and Inland speakers of NE Cree have been suggested (Dyck et al. 2006; MacKenzie 1980), yet not systematically documented. Variation in the data among speakers may be influenced by sub-dialectal differences. For this study, the speakers were asked to say each word in isolation, separated by pauses. Methods of data collection differed among speakers.

A trained linguist, (S. Johansson) who does not speak NE Cree, prompted LBS for words orally by being given the English translation. She recorded each word twice. MN, a graduate level linguistics student, recorded herself citing the words in NE Cree while reading the English translations. She provided two tokens for each word. $\mathrm{MN}$ also provided $\mathrm{JN}$ with the English translation for each word orthographically, and he read each word once into a recording device.

The tokens were collected through a translation elicitation technique. A randomized list of word pairs was used, which contrasted words with and without the $/+\mathrm{h} /$ morpheme. An example of contrasting word pair is: 'chî.mân[h] 'boat' and chî.'mâ.n(+h) 'boat (pl.)'. The original list contains 215 items, although speakers omitted or altered certain words if they were not in their vocabulary, or if speakers used a different word other than the one provided for a given translation. The data was collected using an Edirol 24 bit digital recorder and a table mounted Sony ECM-MS907 microphone. ${ }^{3}$

\subsection{Data analysis}

To address the first research question, whether accent shifts with the addition of the $/+\mathrm{h} /$ morphemes as predicted by previous literature, I measured the pitch of the ultimate, penultimate, and antepenultimate syllables in words with and without the $/+\mathrm{h} /$ morpheme. I determined where the accent of a token is produced by measuring the average pitch of the non-final and final syllables in each token. ${ }^{4}$ Whether accent

\footnotetext{
${ }^{3}$ The exact settings for the recording device are unavailable.

${ }^{4}$ Measures of intensity are unreliable from the data as a table-mounted rather than head-mounted microphone was used.
} 
is final or non-final in any given word was determined through acoustic measurements of mean pitch value. ${ }^{5}$ If the pitch of the non-final vowel was higher than the final vowel, I considered the accent to be non-final. If the average pitch of the final vowel was higher than the non-final vowel, I considered the accent to be final. To address the second research question, I provide a description of how each of the three speakers uses creaky voice word-finally as it relates to words with the $/+\mathrm{h} /$ morpheme. This was determined impressionistically using perceptual auditory cues, supported by striation patterns in the waveforms, and a low, irregular F0, as analyzed in Praat (Boersma and Weenink 2018). In addressing the last research question, I explored how pitch slope might interact with the presence of the $/+\mathrm{h} / \mathrm{morpheme}$. This exploration was motivated by the finding that accent shift may not reliably occur in all speakers. How the slope of the pitch change between accented and unaccented syllables relates to the $/+\mathrm{h} /$ morpheme was determined by measuring the final syllable value for pitch and subtracting from it the non-final syllable value for pitch.

\section{Results}

\subsection{Accent shift}

The findings from measures of pitch suggest that each speaker in this study produces four (rather than two, as expected) classes of words, and the way they use these classes is different for each speaker. That is to say, each speaker may create a different accent profile for the same word. The four classes are: (a) words with the $/+\mathrm{h} /$ affix and final accent, (b) words with the $/+\mathrm{h} /$ affix and non-final accent, (c) words with no affix and final accent, and (d) words with no affix and non-final accent. This tentative finding differs from previous descriptions of NE Cree. Refer to Table 6 for examples of unexpected non-final accent placement in words where a final-accent pattern is predicted.

Table 6. Examples of unexpected accent placements

\begin{tabular}{ccc}
\hline Speaker & Predicted accent placement & Actual accent placement \\
\hline LBS & $k \hat{a} . n i$. 'chî $(+h)$ 'sweaters' & 'kâ.ni.chî. $(+h)$ 'sweaters' \\
MN & $\hat{u} h . ' k u . m(+h)$ 'someone's grandmother' & 'ûh.ku.m $(+h)$ 'someone's grandmother' \\
JN & $m \hat{\imath}$. 'wi.t $(+h)$ 'suitcases' & 'mî.wi.t $(+h)$ 'suitcases' \\
\hline
\end{tabular}

\subsection{Other phenomena - pitch slope}

After observing a total of four, not two, accentual patterns for words with and without $/+h /$, I engaged in measuring pitch slopes, in order to further characterize this unexpected result and addressing research question three. Pitch slope is a measurement obtained by taking the final syllable value for pitch and subtracting from it the non-final syllable value for pitch. A positive slope indicates that pitch is higher on the non-final syllable, whereas a negative slope indicates that pitch is higher on the word-final syllable. Different patterns of pitch slope are observed in each of the four word patterns. More specifically, as shown below in Figure 1, all three speakers have a steeper slope of pitch change in words with a non-final accent as compared to words with a final accent. This pattern is mirrored in each speaker in the slope of pitch change in words that are without affix and those that have the $/+h /$ affix. In other words, when a word has the $/+\mathrm{h} /$ affix or is finally accented, the slope of the pitch change appears to become more level. Whereas,

\footnotetext{
${ }^{5}$ It should be noted that peak pitch would be a more reliable indicator, due to the "rising" nature of accent on a single vowel in NE Cree. That is to say, the rise in pitch rather than overall average pitch characterizes pitch accent in NE Cree.
} 
if a word is without affix and non-finally accented, the slope of pitch change appears to be greater and negative (falling).

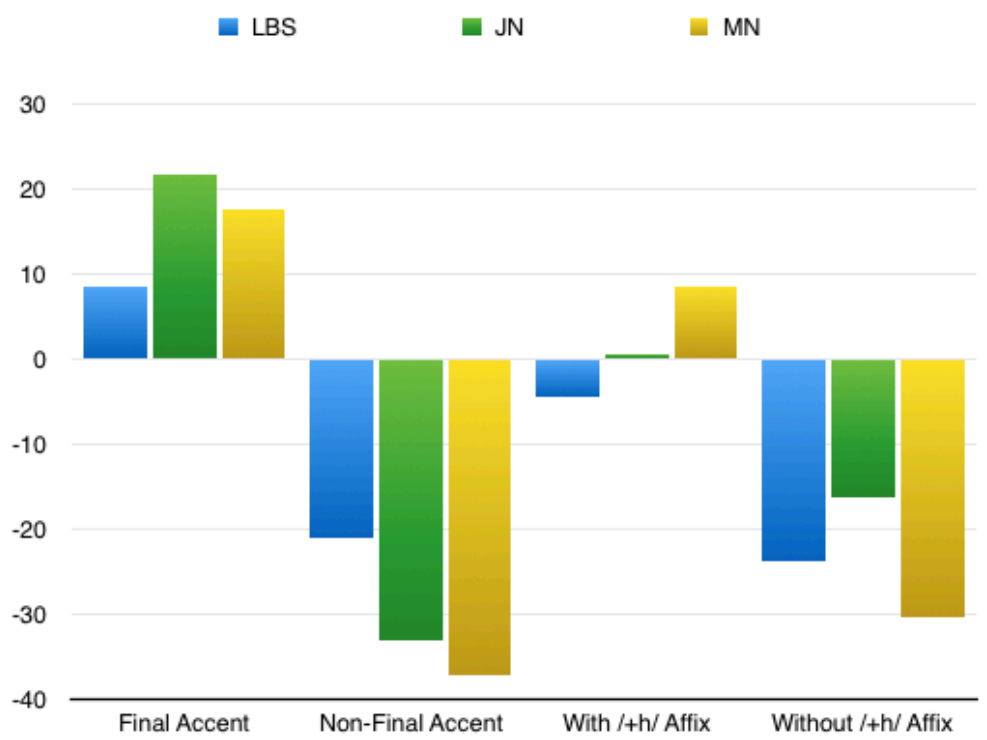

Figure 1. Slopes of pitch change by speaker

Spectrogram illustrations of falling and level pitch slope in words with the $/+\mathrm{h} /$ affix and without affix are provided in (3) to (4).

(3) Words with the $/+\mathrm{h} /$ morpheme and level pitch slope

a. kânichî $(+h)$ 'sweaters'

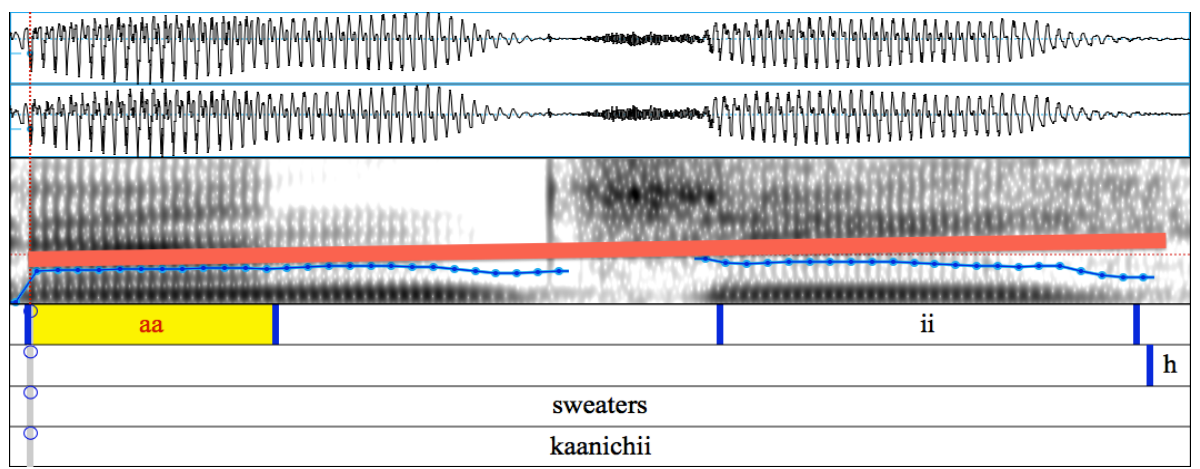


b. miyiu $(+h)$ 'dead bodies'

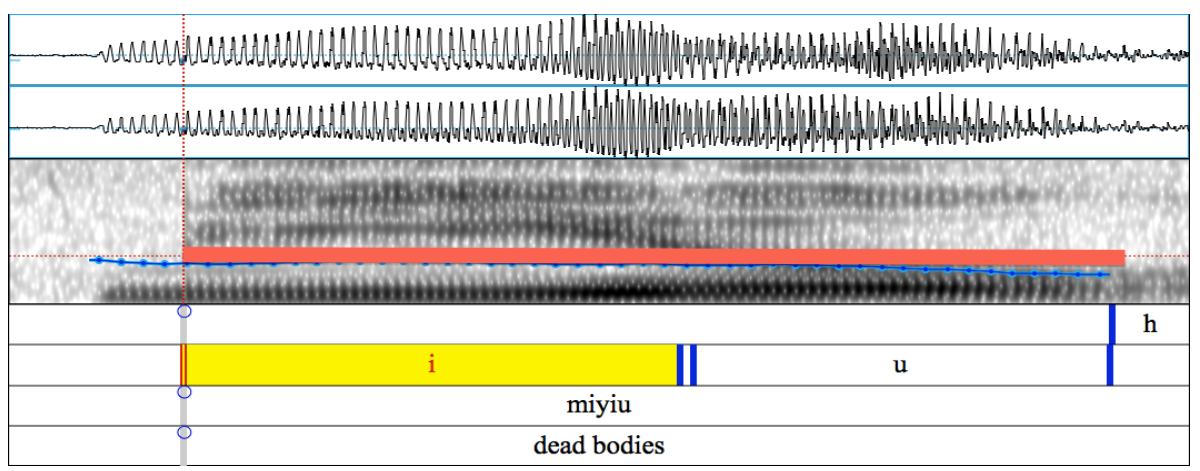

(4) Word with no affix and level pitch slope

a. mîwit 'suit case'

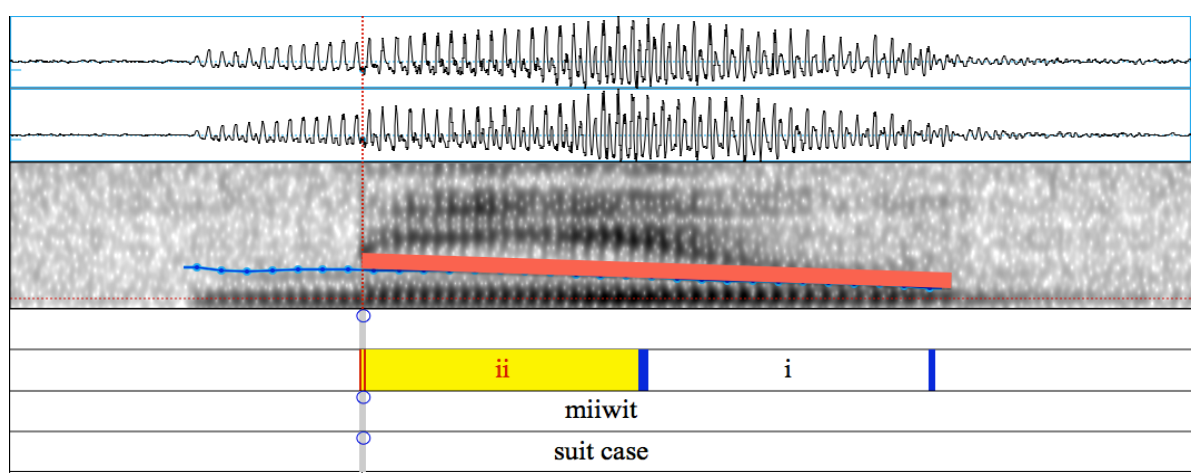

b. miyiu 'dead body'

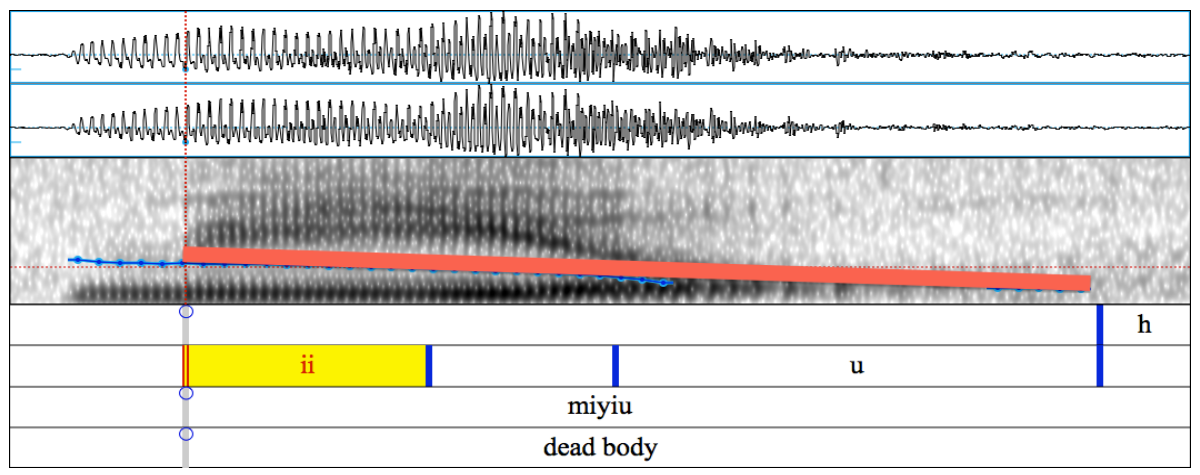

\subsection{Voice quality}

Due to previous anecdotal observations of voice quality changes with / $\mathrm{h} /$ morpheme suffixation, I additionally investigated whether voice quality change co-occurs with the pitch slopes observed. I coded for voice quality categorically as "creaky" or "modal". This was determined according to perceptual auditory cues and striation patterns in the waveforms (widely spaced, sporadic vertical striations), and a low, irregular F0. I matched each token with its contrasting token and performed a comparative analysis to determine where on the continuum of phonation types each segment lies in relation to its contrasting token. For example, I compared the token without affix uniwî ' $[\mathrm{h}]$ his/her cheek' with the counterpart with / $+\mathrm{h} /$ affix uniwî $(+h)$ 'his/her cheeks' and determined if the final vowel of each word was creakier or more modal than the other. In the speech of all three speakers, the final vowel in finally accented words tends to be more 
modal in voicing and the final sonorant in non-finally accented words tend to have creaky voicing. Similarly, all speakers use creaky voice in words without the $/+\mathrm{h} /$ morphemes that are non-finally accented. Where the speakers differ is in words without the $/+\mathrm{h} /$ morphemes that are finally accented. It is unclear whether creaky voice may be a cue to the absence of the $/+h /$ morphemes. Creaky voice may occur as a phonetic correlate of low pitch, or simply, of utterance finality. However, modal voice does appear to be a reliable indicator of the presence of the $/+\mathrm{h} /$ morphemes in all three speakers. As these observations are dependant on researcher perception, further research is required. Examples of modal voice and creaky voice are provided in (5) and (6).

(5) Creaky Voice (uniwii 'his or her cheek')

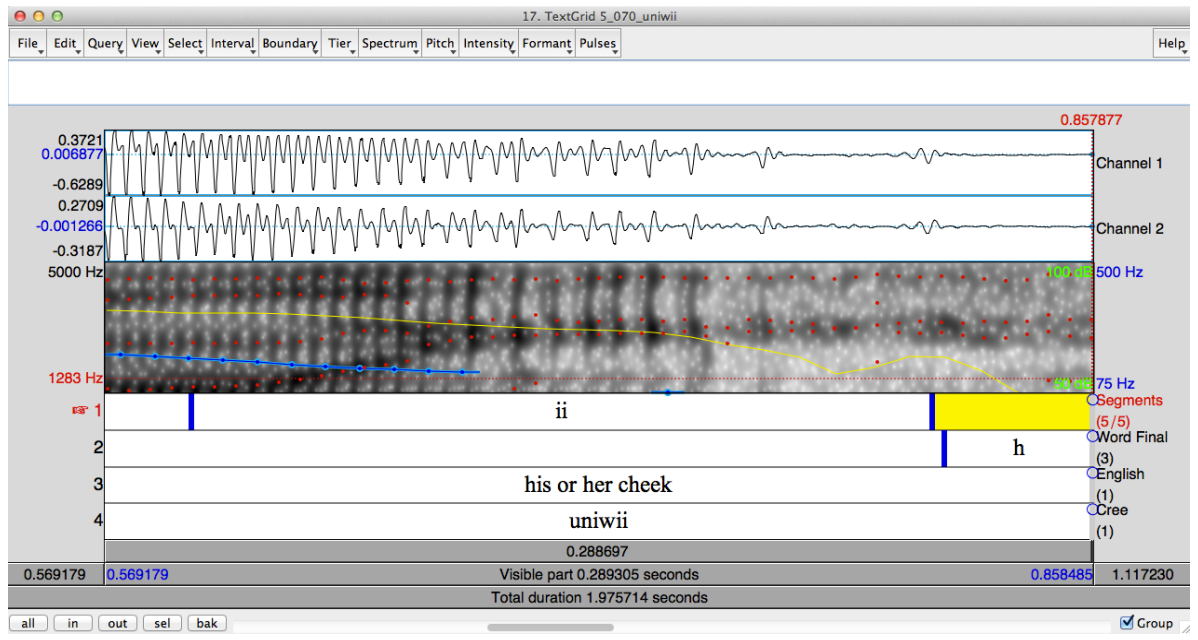

(6) Modal Voice (uniwii(+h) 'his or her cheeks')

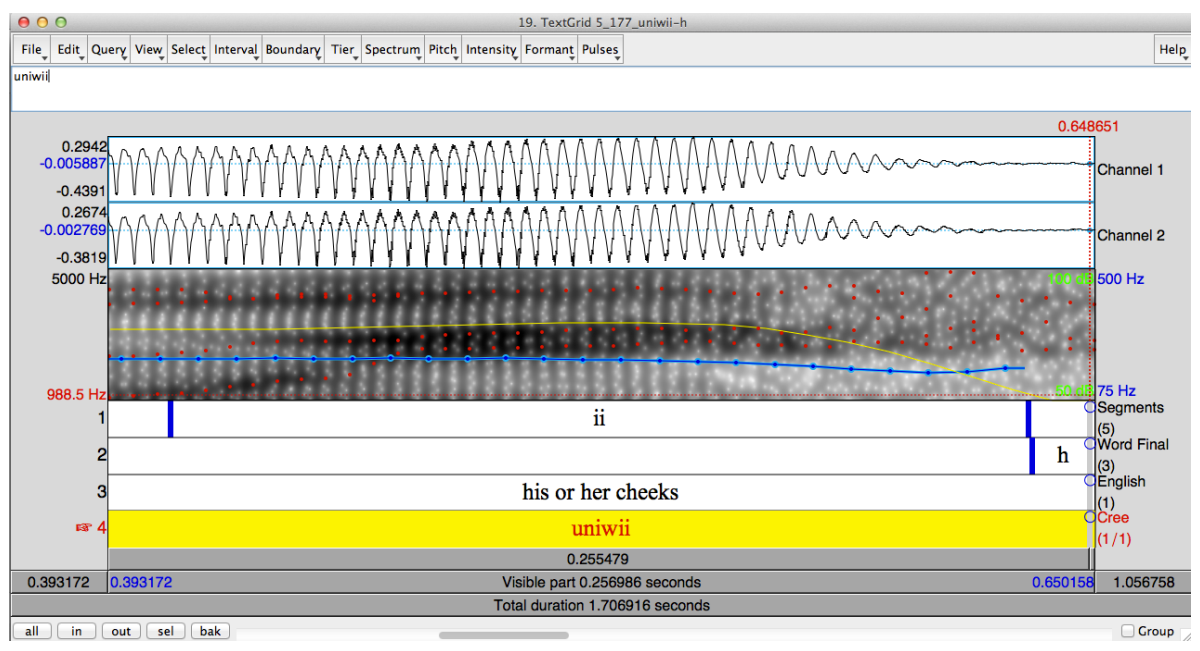

\section{Discussion}

According to the findings in this exploratory study, it is possible that slope, in combination with modal voice, may be the most reliable indicator for the presence of the $/+\mathrm{h} /$ morpheme. However, this suggestion stands in contrast to earlier observations on NE Cree accent, suggesting that accent shift is an indicator of the $/+\mathrm{h} /$ morpheme. The speakers in the present study appear to produce both final and non-final accent patterns on words that have a $/+h /$ morpheme. In NE Cree, rather than a rising inflection on a single syllable, I suggest that a level or rising pitch slope on two adjacent accented syllables may be relevant. Evidence for 
an alteration in pitch slope with the addition of $\mathrm{a} / \mathrm{h} / \mathrm{morpheme}$ can be drawn from comparative evidence on pitch patterns in related Algonquian languages. The $/ \mathrm{h} / \mathrm{suffix}$ derives historically from a word-final short vowel, and in NE Cree, word-final short vowels are deleted (MacKenzie 1980). In the related Algonquian language Maliseet-Passamaquoddy, word-final vowels are also deleted, yet remain detectable through a rising inflection on the accented vowel (Teeter 1971).

In NE Cree, in words with the $/+h /$ morphemes, the pitch slope might be level. I suggest that one way to account for this observation is to posit that such words have a pitch accent on the non-final syllable. Since there is no drop in pitch, these words must have a pitch accent or high tone on the final syllable as well. If the $/+\mathrm{h} /$ morpheme is accented, I hypothesize that it may have an underlyingly phonemic $\mathrm{H}$ (high) tone. The $/+\mathrm{h} /$ morphemes might also be represented phonologically as $/+\mathrm{H} /$, i.e., a grammatical high tone. ${ }^{6}$ In addition, I hypothesize that this $\mathrm{H}$ tone interacts with a $\mathrm{H}$ tone that is metrically assigned to non-finally pitch-accented syllables. When no $/+\mathrm{h} /$ morpheme is present word-finally, there is no $\mathrm{H}$ tone word-finally, but still an $\mathrm{H}$ tone (pitch accent) non-word-finally. In this case, to emphasize the lack of a H-toned morpheme, speakers might increase the falling pitch slope between the non-final H-toned syllable and the final syllable, which lacks $\mathrm{H}$ tone, by means of adding an enhancement feature [ + constricted glottis], which would serve to lower pitch even further, given the pitch-lowering effect of creaky voicing resulting from glottal constriction. Speakers might also choose to not use the enhancement feature [+constricted glottis] in this situation, resulting in a falling word-final tone pattern which does not have as steep a falling pitch slope. In contrast, when a word has a / $+\mathrm{h} /$ morpheme word finally, it would have two $\mathrm{H}$ tones, one on the word-final $/+\mathrm{h} /$ affix, and one on the non-finally accented syllable. Pitch would, therefore, remain level and the phonation of the final syllable would not be affected.

A word with no / $+\mathrm{h} /$ morpheme would be phonemically represented as having one pitch accent on the non-final syllable. Phonetically, the accented syllable is produced with a relatively high pitch as compared to the final syllable. This creates a falling pitch contour from the non-final to the final syllable. In contrast, a word with a $/+\mathrm{h} /$ morpheme would be phonemically represented with a pitch accent on the non-final syllable, and a second accent on the final syllable, contributed by the $/+h / a f f i x$. Phonetically, this would result in a level (or somewhat rising) pitch pattern.

\section{Conclusion and limitations}

In conclusion, the present descriptive exploration into the $/+\mathrm{h} /$ morphemes does not appear to support earlier observations that the $/+\mathrm{h} /$ morpheme is correlated with a shift in accent to the final syllable. Rather, the findings suggest that words without $/+\mathrm{h} /$ may have a falling tone pattern, whereas words with $/+\mathrm{h} / \mathrm{may}$ have a level tone pattern. I suggest that slope, in combination with modal voice may be the best diagnostic of the presence of $/+h /$ in NE Cree. However, there are limitations that must be mentioned. One limitation pertains to the variability of the recording environment and placement of equipment, which affected the quality of the data. Each of the three recording sessions was not consistent across speakers, which made it necessary to analyze the data of each speaker in isolation. Another limitation is that findings in the present study rely on single word elicitation rather than spontaneous speech. Also, sub-dialectal differences have been suggested and this may have introduced variation into the data. Nonetheless, the results from the present exploratory study indicate several areas worthy of further research.

Acknowledgments. This paper comprises a section of this authors Master of Arts Thesis and the author gratefully acknowledges the support and direction from her supervisors. The author takes all responsibility for the content of this paper, including all errors and omissions.

\footnotetext{
${ }^{6}$ I use the word "tone" to refer to the use of pitch to distinguish grammatical meaning, which, in the present argument, is inanimate plural or animate obviative. This is not to say that NE Cree is a tone language, such as Mandarin.
} 


\section{References}

Boersma, Paul, and David Weenink. 2018. Praat: doing phonetics by computer [Computer Program]. http://www.praat.org/

Dyck, Carrie, Julie Brittain, and Marguerite MacKenzie. 2006. Northern East Cree accent. In Actes du congrès annuel de l'Association canadienne de linguistique 2006/ Proceedings of the 2006 annual conference of the Canadian Linguistic Association, ed. Claire Gurski et Milica Radišic.

Dyck, Carrie, Marie-Odile Junker, and Kelly Logan. 2010. Phonetic and phonological evidence for a short vowel merger in Southern East Cree. Proceedings of the 15th Annual Workshop on the Structure and Constituency of the Languages of the Americas. UBC Working Papers in Linguistics 29: 98-114.

MacKenzie, Marguerite. 1980. Towards a Dialectology of Cree-Montagnais-Naskapi. Doctoral dissertation, University of Toronto.

Stevens, K. N., and Keyser, S. J. 2010. Quantal theory, enhancement and overlap. Journal of Phonetics 38: $10-19$.

Teeter, Karl V. 1971. The main features of Malecite-Passamaquoddy grammar. In University of California Publications in Linguistics, vol. 65: Studies in American Indian Languages, ed. Jesse Sawyer, 191249. Berkeley: University of Californian Press. 